\title{
Escritórios de Gestão de Projetos no Setor Público à Luz do Paradigma da Nova Administração Pública
}

\section{Project Management Offices in the Public Sector in Light of the New Public Management Paradigm}

\author{
Antony Melo \\ Universidade Federal do Rio Grande (FURG) \\ E-mail: abmelo92@gmail.com \\ Décio Bittencourt Dolci \\ Universidade Federal do Rio Grande (FURG) \\ E-mail: dbdolci@gmail.com \\ Lucas Santos Cerqueira \\ Universidade Federal do Rio Grande (FURG) \\ E-mail: lucasscerqueira@gmail.com
}

Resumo: Esse estudo analisa a relação entre a adoção de Escritórios de Gestão de Projetos (PMOs) em organizações públicas e os pressupostos do paradigma da New Public Management (NPM). Trata-se de uma pesquisa qualitativa, um estudo multicaso, que analisa as percepções dos gestores de dois PMOs. Os resultados indicam um forte alinhamento dessas iniciativas com os pressupostos da NPM, presente tanto na implantação das unidades analisadas como em práticas e métodos gerenciais por elas realizados ou disseminados. Espera-se que este estudo possa inspirar gestores públicos no planejamento e na implementação de práticas de gestão de projetos, assim como pesquisadores interessados na temática.

Palavras-Chave: Gestão de Projetos; Escritório de Gestão de Projetos; PMO; Nova Administração Pública.

\begin{abstract}
This study analyzes the relationship between the adoption of Project Management Offices (PMOs) in public organizations and the New Public Management (NPM) paradigm assumptions. This is a qualitative research, a multisite study, analyzing public organizations PMO managers' perceptions. The results indicate a strong association of these initiatives with the assumptions of the NPM, present both in the implementation of the analyzed units and in the practices and management methods that they perform or disseminate. It is to be hoped that this study will help public managers in the planning and implementation of project management practices, as well as researchers interested in the subject.
\end{abstract}

Keywords: Project Management; Project Management Offices; PMO; New Public Management. 
MELO, Antony; DOLCI, Décio Bittencourt; CERQUEIRA, Lucas Santos. Escritórios de Gestão de Projetos no Setor Público à Luz do Paradigma da Nova Administração Pública

\section{Introdução}

A gestão de projetos está gradualmente tornando-se um fator fundamental no desempenho de organizações do setor público, visto que projetos de diferentes tamanhos e estruturas têm sofrido rotineiros fracassos, como estouro de prazo e orçamento, redefinições de escopo, além das falhas na prestação de contas (Carvalho \& Piscopo, 2014). No sentido de atingir melhores resultados, os Escritórios de Gestão de Projetos (EGP), ou Project Management Office (PMO) - denominação em inglês e amplamente utilizada, aparecem como as unidades organizacionais responsáveis pela minimização de problemas gerenciais e, também, pela disseminação das práticas de gerenciamento de projetos por toda a organização, possibilitando, entre outros benefícios, uma diminuição nas falhas e garantindo que os projetos mais importantes sejam priorizados (Maximiano \& Anselmo, 2006; Aubry \& Hobbs, 2011).

Segundo Englund, Graham e Dismore (2003), os Escritórios de Gerenciamento de Projetos são capazes de mudar o modo como às organizações gerenciam e "pensam" sobre o gerenciamento de projetos. No entanto, de acordo com Valle, Soares, Finocchio Jr. e Silva (2010) faltam estudos científicos acerca da percepção dos profissionais da área sobre qual o papel dos Escritórios de Projetos nas organizações. Seja na organização pública ou privada, uma organização bem sucedida tem um fluxo de projetos bem definidos, fator essencial para enfrentar as mudanças inevitáveis (Cleland \& Ireland, 2002).

Segundo Peters (2008), a reflexão sobre a reforma administrativa e gerencial no setor público é necessária em virtude das transformações que as organizações públicas e privadas estão passando, exigindo maior qualificação profissional, comprometimento e flexibilidade para executar as tarefas. No mundo globalizado, é imprescindível a utilização de novas competências e estratégias na administração do patrimônio público, em que a aplicação de técnicas modernas de gerenciamento e controle são fundamentais (Bresser-Pereira, 1998).

Frente ao desafio de melhorar a gestão pública, o presente trabalho soma-se a outros estudos que visam a contribuir para o conhecimento científico partindo de questões interessadas no paradigma da Nova Administração Pública. Considera-se que ainda é pouco explorada sua influência no ciclo de vida do PMO, desde a percepção da necessidade de sua implantação até seus resultados organizacionais, seja em projetos, seja em outros aspectos, bem como sua

Revista Brasileira de Políticas Públicas e Internacionais, v.4, n.1, julho/2019, pp. 05-28. 
MELO, Antony; DOLCI, Décio Bittencourt; CERQUEIRA, Lucas Santos. Escritórios de Gestão de Projetos no Setor Público à Luz do Paradigma da Nova Administração Pública

institucionalização em órgãos com autoridade para realizar os trabalhos do Estado. Acredita-se que este estudo traga contribuições aos gestores públicos no que tange o planejamento e implantação de Escritórios de Gestão de Projetos, bem como para os pesquisadores que buscam desenvolver outras pesquisas nessa temática.

Nesse sentido, frente ao objetivo geral de melhor compreender a adoção dos Escritórios de Gestão de Projetos (PMOs) no setor público à luz do paradigma da Nova Administração Pública, definiram-se os seguintes objetivos específicos focados na percepção dos gestores do escritório de projetos: (1) identificar os diferentes facilitadores e inibidores, tanto na implantação como na realização das funções do PMO; e (2) associar suas funções aos benefícios no desempenho organizacional, sob o paradigma da Nova Administração Pública.

O presente artigo está organizado em cinco seções. Além dessa seção introdutória, a seção 2 expõe o referencial teórico, o qual compreende o gerenciamento de projetos, os escritórios de gestão de projetos e o paradigma da Nova Administração Pública. A seção 3 apresenta a metodologia utilizada na pesquisa. A seguir, na seção 4, são divulgados os resultados, sua síntese e discussão à luz do paradigma da Nova Administração Pública. Por fim, conclui-se com as considerações finais na seção 5.

\section{Referencial Teórico}

Nesta seção, apresentam-se fundamentos que dão suporte teórico a presente investigação. A subseção 2.1 traz definições sobre gestão de projetos, aborda o ciclo de vida de projetos e versa sobre diferentes perspectivas de análise de sucesso em gestão de projetos. Na mesma direção, a subseção 2.2 apresenta o escritório de gestão de projetos como uma unidade organizacional capaz de melhorar as relações entre gerenciamento e projeto público. O paradigma da Nova Administração Pública é abordado na subseção 2.3 após uma contextualização baseada em fatos históricos que impulsionaram a adoção de novas práticas de gestão no setor público.

\subsection{Gerenciamento de Projetos}

Revista Brasileira de Políticas Públicas e Internacionais, v.4, n.1, julho/2019, pp. 05-28. 
MELO, Antony; DOLCI, Décio Bittencourt; CERQUEIRA, Lucas Santos. Escritórios de Gestão de Projetos no Setor Público à Luz do Paradigma da Nova Administração Pública

O Ciclo de vida de um projeto compreende as fases pelas quais um projeto passa, desde o início até o término. As fases podem ser definidas por objetivos funcionais ou parciais, resultados ou entregas, marcos específicos no escopo, ou disponibilidade financeira. Embora todos os projetos tenham um início e um fim definidos, as fases poderão variar de acordo com o projeto. O ciclo de vida apresenta uma estrutura genérica para o gerenciamento do projeto, independentemente do trabalho envolvido: início do projeto, organização e preparação, execução do trabalho do projeto, e encerramento do projeto (PMI, 2014).

Em uma perspectiva de ciclo de vida estendido do projeto, engloba fases desde aquelas que antecedem ao início do projeto, como: identificação, categorização, avaliação, seleção, priorização, balanceamento até outras posteriores ao seu término, como operação e avaliação dos resultados e benefícios (Valle et al., 2010). É válido observar que esta é a perspectiva de análise adotada no presente estudo.

O gerenciamento de projetos corresponde à aplicação do conhecimento, habilidades, ferramentas e técnicas, no âmbito do próprio projeto, a fim de suprir os requisitos do mesmo. Ainda de acordo com o PMI (2014), o gerenciamento de projetos agrupa, de forma lógica e coerente, seus processos em cinco grupos: iniciação; planejamento; execução; monitoramento e controle; e encerramento.

Nessa perspectiva, segundo Kerzner (2009), o gerenciamento de projetos envolve o planejamento e monitoramento de projetos, incluindo itens como: definiçãa dos requisitos de trabalho; definição da quantidade e qualidade de trabalho; definição dos recursos necessários; monitoramento do projeto; acompanhamento do progresso; comparação do resultado atual com o resultado previsto; análise do impacto; e realização de ajustes.

De acordo com Valle et al. (2010), um projeto bem-sucedido é aquele capaz de produzir todas entregas planejadas dentro do cronograma e do orçamento previsto, atendendo todas especificações de performance e qualidade, atingindo suas metas e seus propósitos, de modo a alcançar as expectativas das partes interessadas. Ainda em relação à avaliação de sucesso em projetos, é válido observar que projetos se diferem em tamanho, singularidade e complexidade. Dessa forma, o critério para medir o sucesso pode variar de projeto para projeto (Müller \& Turner, 2007).

Revista Brasileira de Políticas Públicas e Internacionais, v.4, n.1, julho/2019, pp. 05-28. 
MELO, Antony; DOLCI, Décio Bittencourt; CERQUEIRA, Lucas Santos. Escritórios de Gestão de Projetos no Setor Público à Luz do Paradigma da Nova Administração Pública

Conforme Westerveld (2003), é improvável que haja um consenso em relação a um conjunto de critérios universal sobre a definição de sucesso em projetos. Sistemas tradicionais de gerenciamento de projetos, os quais levam apenas em consideração fatores como custo, tempo, qualidade e necessidades técnicas, têm sido considerados ineficientes (Bourne, Mills, Wilcox, Neely, \& Platts, 2000; Walton \& Dawson, 2001). Nesse sentido, nota-se que o sucesso em projetos é um fator multidimensional e que há diferentes visões em diferentes fases de um projeto (Bryde, 2003; Shenhar, Levy \& Dvir, 1997).

No contexto da administração pública, segundo Meredith e Mantel Jr. (2003), o gerenciamento de projetos deve ser visto como uma prática atual, uma vez que inclui novas práticas de gestão, apresentando autonomia e estratégia bem alinhada, com intuito de entregar projetos com maior eficiência e qualidade. Complementarmente, há de se considerar certas especificidades no gerenciamento desses projetos. Conforme a extensão do PMI/PMBOK(2006) para projetos públicos, destacam-se três características: a necessidade do projeto se sujeitar a leis e regulamentações adicionais que podem significativamente impactar os projetos; o processo de prestação de contas ser mais desafiador, havendo demandas de informações especiais para um maior número de participantes externos ao projeto, como, por exemplo, membros da sociedade, imprensa e outros níveis de governo; o domínio dos processos para a obtenção e utilização dos recursos públicos.

Nessa direção, a implantação de um PMO na estrutura pública pode melhorar não só o alinhamento estratégico da organização e, consequentemente, obter um aumento no desempenho em termos de projetos de nível estratégico (Maximiano \& Anselmo, 2006; Carvalho \& Piscopo, 2014) como também auxiliar em um gerenciamento mais adequado às características dos projetos públicos.

\subsection{Escritórios de Gestão de Projetos (PMOs)}

O Escritório de Gestão de Projetos é uma estrutura da organização onde os processos de governança relacionados ao projeto são padronizados, de forma centralizada e coordenada, facilitando o compartilhamento de recursos, metodologias, ferramentas e técnicas. As funções

do escritório de projetos são variadas, abrangendo desde suporte e apoio ao gerenciamento de

Revista Brasileira de Políticas Públicas e Internacionais, v.4, n.1, julho/2019, pp. 05-28. 
MELO, Antony; DOLCI, Décio Bittencourt; CERQUEIRA, Lucas Santos. Escritórios de Gestão de Projetos no Setor Público à Luz do Paradigma da Nova Administração Pública

projetos até responsabilidade real de gerenciamento de projetos sob sua competência (PMI, 2014). Conforme Valle et al. (2010), destacam-se entre as principais atribuições de um Escritório de Gestão de Projetos o fornecimento de treinamento, software, padrões e procedimentos, podendo chegar ao gerenciamento de forma direta e à responsabilidade de executar o próprio projeto.

Segundo Carneiro (2012), o Escritório de Gestão de Projetos é o núcleo que qualifica uma empresa (se estratégico) ou um setor (se departamental) a melhor gerir o portfólio dos projetos. O autor ainda destaca que as principais funções do escritório de projetos são: de controle, auditoria e revisão dos projetos; treinamento e suporte aos gerentes de projetos; estruturação de ambiente de projetos através de processos, metodologia e software; análise, priorização e seleção de projetos, alinhados ao planejamento estratégico e outras decisões gerenciais; e funções de gestão de recursos humanos de projetos.

Parchami Jalal e Matin Koosha (2014), com base em levantamento realizado pelo Project Management Solutions em 2010, apresentam como os principais benefícios do PMO: a diminuição de projetos falhos; o aumento nas entregas de projetos antes do cronograma; o aumento nos projetos entregues abaixo do orçamento; o aumento de produtividade; e o aumento na capacidade de recursos.

Pesquisas realizadas pela PMSolutions em 2014, com 432 companhias $(75 \%$ da América do Norte, $12 \%$ da Europa, $4 \%$ das Américas Central e Sul, 3\% da África e 3\% da Ásia), apontaram que organizações com escritórios de gestão de projetos obtiveram um aumento de $45 \%$ no alinhamento dos projetos com os objetivos organizacionais, diminuição de $27 \%$ em projetos falhos e uma economia de até US\$ 101.000 por projeto. Além disso, esta pesquisa aponta que $90 \%$ das empresas de grande porte (com receita acima de US\$ 1B por ano) possuem escritórios de projetos, enquanto apenas $61 \%$ das empresas de pequeno porte (com receita abaixo de US\$100M por ano) apresentam o escritório de projetos.

Por outro lado, os maiores desafios encontrados pelos Escritório de Gestão de Projetos estão no fato de que eles são percebidos, para algumas organizações, como caros e criam, assim, uma resistência a mudanças (PMSolutions, 2014). Segundo Maximiano e Anselmo (2006), uma dificuldade encontrada na atuação das funções do PMO é o grau de autonomia do

Revista Brasileira de Políticas Públicas e Internacionais, v.4, n.1, julho/2019, pp. 05-28. 
MELO, Antony; DOLCI, Décio Bittencourt; CERQUEIRA, Lucas Santos. Escritórios de Gestão de Projetos no Setor Público à Luz do Paradigma da Nova Administração Pública

executivo principal, essa redução de autoridade está claramente ligada aos problemas de desempenho das funções do escritório de gestão de projetos. Os autores também ressaltam que o apoio da cúpula da organização ao gestor do PMO é de extrema importância para o desempenho dos projetos organizacionais.

No contexto da administração pública, segundo Teixeira e Salles (2006), a ausência de uma cultura de gerenciamento de projetos foi uma das principais dificuldades encontradas, pois: i) os servidores públicos não compreendiam a função do monitoramento sistemático do prazo, escopo, qualidade e riscos; ii) o PMO aparece como uma prática eficaz, pois funciona como um esforço contínuo, uma vez definidos os projetos prioritários da instituição pública, e iii) visa assegurar que a metodologia seja aplicada à risca, garantindo a execução do que é, verdadeiramente, prioritário.

De acordo com Pestana e Valente (2010), o gerenciamento de projetos é uma prática usada por organizações de diversos setores inclusive no contexto da administração pública, e vem sendo imprescindível para transformar o planejamento em resultados, otimizar a alocação de recursos, diminuir os riscos e trazer mais eficiência à gestão de projetos. Observam os autores que as exigências, por parte dos cidadãos, de serviços públicos com mais qualidade, reforçam a importância da utilização de boas práticas de gerenciamento de projetos no setor público.

Apesar de ser mais frequente no setor privado, a gestão de projetos no setor público está se tornando um fator principal no desempenho organizacional, uma vez que diferentes projetos são realizados e a rotina de fracassos é notória (Carvalho \& Piscopo, 2014). Órgãos da administração pública apresentam resultados negativos com diversos tipos de projetos. Erros como estouros de prazo e orçamento, redefinições de escopo e falhas na prestação de contas são recorrentes, resultando no comprometimento da liberação de recursos, trazendo prejuízos para a organização pública (Carvalho \& Piscopo, 2014).

Segundo Olateju, Abdul-Azeez e Alamutu (2011), o PMO na administração pública, com características e atribuições similares a qualquer outro escritório de projetos do setor privado, consiste em uma estrutura estratégica que permite a aplicação de técnicas e ferramentas de gestão auxiliando de forma decisiva a organização a atingir os seus objetivos.

Revista Brasileira de Políticas Públicas e Internacionais, v.4, n.1, julho/2019, pp. 05-28. 
MELO, Antony; DOLCI, Décio Bittencourt; CERQUEIRA, Lucas Santos. Escritórios de Gestão de Projetos no Setor Público à Luz do Paradigma da Nova Administração Pública

Essa introdução ocorre, entre outros motivos, devido a sua aplicação bem-sucedida em organizações privadas (Olateju, Abdul-azeez \& Alamutu, 2011).

\subsection{Nova Administração Pública (NPM)}

Bresser-Pereira (1998) descreve o desenvolvimento da administração pública brasileira em três estágios - patrimonial, burocrático e gerencial. Uma visão evolucionista, em que se percebe a transformação do Estado como um processo de modernização, sem deixar de reconhecer a convivência entre novas e velhas formas em diferentes estágios, como observa Costa e Costa (2016), dirige-se a presente pesquisa pelas características que mais se pronunciam na abordagem gerencial.

As premissas da implantação do modelo gerencial na Administração Pública advêm de fatores estruturais (internos) e conjunturais (externos) que culminaram na incapacidade de o Estado prover as demandas sociais e os serviços públicos com racionalidade e eficiência. Não se pode deixar de citar que o receituário da abertura de mercados e liberalização econômica, advindos do Consenso de Washington na década de 80, também influenciou tais reformulações do papel estatal, dentre outras:

I. A condição físcal do Estado foi diretamente afetada pela crise do petróleo de 1973, com consequências: i) deteriorou sua capacidade de manutenção do Walfare State, Estado do bem-estar; ii), o modo Keynesiano de intervenção na economia; e iii) prejudicou o desempenho de suas atividades essenciais (Abrúcio, 1997; Rua, 1997).

II. O esgotamento do modelo burocrático weberiano, que pregava a impessoalidade, racionalidade e imparcialidade na gestão, pela insuficiência em atender às demandas contemporâneas das sociedades pós-industriais por conta da morosidade e apego às normas, e pelo surgimento das novas tecnologias e da globalização que exigiam um modelo menos rígido (Abrúcio, 1997; Bresser-Pereira, 1998; Rua, 1997).

Na economia, a diminuição do papel do Estado ficou conhecida como Neoliberalismo, que Anderson (1995) cita como base a publicação do livro "Caminho da Servidão" de Hayek, em 1944, mas que os ideais neoliberais se consolidam com a ascensão dos governos de Margareth Thatcher, na Inglaterra, e de Ronan Reagan, nos EUA, entre 80 e 90. Já o

Revista Brasileira de Políticas Públicas e Internacionais, v.4, n.1, julho/2019, pp. 05-28. 
MELO, Antony; DOLCI, Décio Bittencourt; CERQUEIRA, Lucas Santos. Escritórios de Gestão de Projetos no Setor Público à Luz do Paradigma da Nova Administração Pública

movimento para melhorar a eficiência do Estado na prestação dos serviços e gastos públicos ficou conhecido como New Public Management, Nova Administração Pública, Administração Pública Gerencial, Gerencialismo ou Modelo Gerencial (Abrúcio, 1997; Bresser-Pereira, 1998; Secchi, 2009). No Brasil, o neoliberalismo foi adotado como agenda política prioritária nos governos FHC de 1995-2002, que culminou na Reforma do Estado, marcada principalmente pelo viés privatizante e de enfraquecimento do Estado, e pela introdução do Gerencialismo no país. Cintra e Vieira (2007) afirmam que, ao tratar influências externas, as organizações públicas e privadas assemelham-se, pois ambas devem adaptar-se às demandas que impulsionam a novas mudanças.

Em diversos países como Inglaterra, Nova Zelândia e Austrália construíram-se progressivamente as bases e pressupostos da administração pública gerencial (Bresser-Pereira, 1998), a saber: a) descentralização, em termos políticos, transferindo recursos e atribuições para os níveis políticos regionais e locais; b) descentralização administrativa, através da delegação de autoridade para os administradores públicos transformados em gerentes crescentemente autônomos; c) organizações com poucos níveis hierárquicos ao invés de piramidal; d) organizações flexíveis ao invés de unitárias e monolíticas, nas quais as ideias de multiplicidade, de competição administrada e de conflito tenham lugar; e) pressuposto da confiança limitada e não da desconfiança total; f) definição dos objetivos a serem atingidos pelas unidades descentralizadas na forma de indicadores de desempenho, sempre que possível quantitativos, que constituirão o centro do contrato de gestão entre o ministro e o responsável pelo órgão que está sendo transformado em agência; g) controle por resultados, a posteriori, ao invés do controle rígido, passo a passo, dos processos administrativos; e h) administração voltada para o atendimento do cidadão, ao invés de auto referida.

O conceito de gerencialismo estaria associado à utilização de benchmarks no setor público, de práticas anteriormente exclusiva do setor privado (Secchi, 2009), não na perspectiva da geração de lucros (Bresser-Pereira, 1998), mas na busca por eficiência, eficácia, competividade e na melhoria da qualidade dos serviços públicos (Abrúcio, 1997, Sechhi, 2009), o que Guimarães (2000) considera ser bases da inovação na administração pública, e completa, "são necessários o rompimento com os modelos tradicionais de administrar os recursos

Revista Brasileira de Políticas Públicas e Internacionais, v.4, n.1, julho/2019, pp. 05-28. 
MELO, Antony; DOLCI, Décio Bittencourt; CERQUEIRA, Lucas Santos. Escritórios de Gestão de Projetos no Setor Público à Luz do Paradigma da Nova Administração Pública

públicos e a introdução de uma nova cultura de gestão" (p.127). A adoção de ferramentas como Balanced Scorecard, avaliação de desempenho, gestão da qualidade, gestão de projetos, dentre outros, é consequência dessa reforma feita no setor público brasileiro e da ruptura com o modelo weberiano.

\section{Metodologia}

Para efeito de estudos, é importante evitar o "anacronismo", assinalado por Costa e Costa (2016), ou seja, utilizar conceitos e ideias de uma época para analisar os fatos de outro tempo, avaliar um determinado tempo histórico sob valores que pertençam a esse mesmo tempo. Assim, privilegiou-se examinar a questão do gerenciamento de projetos no setor público por uma lente teórica contemporânea aos fatos, a da Administração Pública Gerencial.

A presente pesquisa se apresenta como um estudo de casos múltiplos, de caráter qualitativo e exploratório. Segundo Yin (2001), o estudo de caso é um estudo empírico que investiga fenômenos em determinados contextos de realidade, quando as questões entre o fenômeno e o contexto não estão claramente compreendidas. O estudo de casos múltiplos é aquele no qual diversos estudos são realizados de forma simultânea, com vários indivíduos ou organizações.

Cabe ressaltar que este estudo adota uma postura de análise dos fenômenos com base nos pressupostos do paradigma interpretativista, que partem de questões interessadas no significado das construções sociais e suas interpretações, conforme expõe o quadro 1 (Burrel \& Morgan, 1979).

Quadro 1: Pressupostos do paradigma interpretativista.

\begin{tabular}{|l|c|}
\hline $\begin{array}{l}\text { Nominalismo } \\
\text { Não admite a existência de qualquer estrutura real para o mundo. Tudo é produto da cognição } \\
\text { do indivíduo. A realidade é produto da própria mente. }\end{array}$ & Ontologia \\
\hline $\begin{array}{l}\text { Interpretativista } \\
\text { O mundo social é relativista, e pode ser entendido do ponto de vista dos indivíduos } \\
\text { envolvidos na atividade estudada. }\end{array}$ & Epistemologia \\
\hline $\begin{array}{l}\text { Voluntarismo } \\
\text { Homem autônomo e possuidor de livre arbítrio. }\end{array}$ & $\begin{array}{c}\text { Natureza } \\
\text { humana }\end{array}$ \\
\hline $\begin{array}{l}\text { Idiográfico (singular) } \\
\text { Entender o mundo social pela obtenção, em primeira mão, do conhecimento sob investigação. } \\
\text { Foco como o indivíduo cria, modifica e interpreta o mundo no qual ele descobre. }\end{array}$ & Metodologia \\
\hline
\end{tabular}

Fonte: Burrel e Morgan (1979).

Revista Brasileira de Políticas Públicas e Internacionais, v.4, n.1, julho/2019, pp. 05-28. 
MELO, Antony; DOLCI, Décio Bittencourt; CERQUEIRA, Lucas Santos. Escritórios de Gestão de Projetos no Setor Público à Luz do Paradigma da Nova Administração Pública

Portanto, com base nesses pressupostos, esta pesquisa parte de questões interessadas na interpretação do sujeito, perspectivas de significados e explicações de seus motivos. Nesse sentido, busca-se compreender a realidade construída e o porquê (motivo) do fenômeno.

Visando a atender ao objetivo da pequisa, buscou-se analisar dimensões organizacionais e esferas administrativas diferentes, resultando na escolha de duas organizações da administração pública direta (mais especificamente nas esferas Estadual e Municipal). É válido apontar que foi realizado um levantamento prévio, em todo Brasil, a fim de buscar Escritórios de Gestão de Projetos inseridos no contexto da Administração Pública, tanto para verificar quantitativamente quanto para identificar as áreas de atuação dos mesmos.

No primeiro momento, procedeu-se com pesquisas no banco de dados Scopus, na ferramenta de pesquisa Google Scholar e em sites da internet utilizando descritores como: PMO; Escritórios de Gestão de Projetos; Escritórios de Gerenciamento de Projetos; EGP; Gestão Pública; e Administração Pública. Além disso, foram realizadas ligações telefônicas para os 26 estados, e suas respectivas capitais, e Distrito Federal. Também entrou-se em contato telefônico com as 50 universidades melhores colocadas no Ranking Universitário Folha 2016, o qual classifica as instituições brasileiras a partir de indicadores de pesquisa, inovação, internacionalização, ensino e mercado. A partir do levantamento, verificou-se a existência de 33 Escritórios de Gestão de Projetos no setor público do Brasil, atuantes nas mais diversas áreas, desde gestão de projetos estruturais de municípios e estados até gestão de projetos de ensino e pesquisa. Destaca-se que foram encontrados apenas dois PMOs no Estado do Rio Grande do Sul.

Nos casos selecionados por conveniência objetivando investigar o PMO nas esferas estadual e municipal, considerou-se a disponibilidade do gestor (especialista) para participar da pesquisa, o tempo de atividade do escritório e a proximidade física do PMO, resultando como objetos de análise para este estudo os Escritórios de Gestão de Projetos do Governo do Estado do Rio Grande do Sul e o da Prefeitura Municipal de Pelotas.

O primeiro contato com estas duas organizações públicas foi através de ligação telefônica. Logo após a confirmação do interesse por parte dos gestores dos PMOs, foram enviados e-mails com a apresentação da proposta de pesquisa. Na sequência, as entrevistas

Revista Brasileira de Políticas Públicas e Internacionais, v.4, n.1, julho/2019, pp. 05-28. 
MELO, Antony; DOLCI, Décio Bittencourt; CERQUEIRA, Lucas Santos. Escritórios de Gestão de Projetos no Setor Público à Luz do Paradigma da Nova Administração Pública

foram agendadas (através de e-mail procedendo, assim, para a etapa de coleta de dados. As entrevistas, conduzidas em abril e maio de 2016, com os gestores responsáveis pelos PMOs do Governo do Estado do Rio Grande do Sul e da Prefeitura de Pelotas foram realizadas pessoalmente nas respectivas Secretarias, com duração de aproximadamente uma hora cada entrevista.

No que se refere ao instrumento de coleta de dados, um roteiro semiestruturado, dividido em cinco blocos, foi desenvolvido para a realização das entrevistas com os gestores responsáveis pelos PMOs das organizações públicas investigadas. O bloco 1 do roteiro inclui questões sobre informações gerais da organização. O bloco 2 abrange informações gerais do respondente. O bloco 3 compreende questões relacionadas às informações gerais sobre a implantação do PMO. O bloco 4 diz respeito às praticas do PMO. E o bloco 5 trata de questões relacionadas ao apoio da Tecnologia da Informação (TI) ao PMO.

Todas as entrevistas foram registradas por meio de gravação de áudio e, posteriormente, transcritas. Adicionalmente, foram aplicados métodos secundários de coleta de dados, os quais consistiram em observação do ambiente da organização para conhecimento de equipamentos, consulta a ferramentas, softwares e site corporativo. A Tabela 1 apresenta o perfil dos gestores entrevistados.

Tabela 1: Características dos Entrevistados

\begin{tabular}{|c|c|c|c|c|}
\hline Entrevistado & Organização & $\begin{array}{c}\text { Tempo de } \\
\text { PMO }\end{array}$ & Cargo & Formação \\
\hline Gestor 1 & $\begin{array}{l}\text { Coordenadoria de Estratégia e } \\
\text { Gestão (CEG) da Prefeitura } \\
\text { Municipal de Pelotas. }\end{array}$ & 3 anos & $\begin{array}{l}\text { Coordenador de } \\
\text { estratégia e } \\
\text { gestão }\end{array}$ & $\begin{array}{c}\text { Tecnólogo em } \\
\text { Processamento de } \\
\text { Dados }\end{array}$ \\
\hline Gestor 2 & $\begin{array}{l}\text { Secretaria do Planejamento, } \\
\text { Mobilidade e Desenvolvimento } \\
\text { Regional do Estado do Rio } \\
\text { Grande do Sul }\end{array}$ & 9 anos & $\begin{array}{l}\text { Coordenador do } \\
\text { Escritório de } \\
\text { Projetos }\end{array}$ & $\begin{array}{l}\text { Mestre em } \\
\text { Engenharia Civil } \\
\text { com ênfase em } \\
\text { Construção } \\
\text { Industrializada }\end{array}$ \\
\hline
\end{tabular}

Fonte: Elaboração Própria (2017).

Revista Brasileira de Políticas Públicas e Internacionais, v.4, n.1, julho/2019, pp. 05-28. 
MELO, Antony; DOLCI, Décio Bittencourt; CERQUEIRA, Lucas Santos. Escritórios de Gestão de Projetos no Setor Público à Luz do Paradigma da Nova Administração Pública

\section{Resultados}

Primeiramente, revelam-se os resultados dos estudos de caso da prefeitura municipal de Pelotas (subseção 4.1) e do governo do Estado do Rio Grande do Sul (subseção 4.2). Após, expõe-se uma síntese dos resultados na subseção 4.3, prosseguindo-se com a discussão à luz do paradigma da Nova Administração Pública na subseção 4.4.

\subsection{PMO na Prefeitura Municipal de Pelotas}

O PMO da Coordenadoria de Estratégia e Gestão (CEG) da Prefeitura Municipal de Pelotas inseriu-se junto à Secretaria de Gestão da Cidade e Mobilidade Urbana (SGCMU). No dia 18 de outubro de 2013, iniciou-se a implantação do PMO, mas seu funcionamento pleno começou somente em outubro de 2014. A adoção deu-se em virtude da necessidade de, por parte do principal gestor público, enxergar, acompanhar e monitorar todos os projetos de forma organizada e padronizada. Além disso, atendeu a necessidade de acompanhar as responsabilidades em relação aos projetos, o que coaduna com a ideia de Carneiro (2012) sobre a importância qualitativa em se ter um PMO para a gestão de projetos.

O PMO da Prefeitura de Pelotas foi institucionalizado por um decreto no dia 23 de janeiro de 2014, compreendendo cerca de trinta pessoas, entre gerentes de projetos, monitores, o Prefeito e a Vice-Prefeita. O escritório visou ao alinhamento do planejamento dos projetos estabelecidos na campanha eleitoral do Prefeito com o Plano Plurianual (PPA) de seu governo, sendo responsável por toda a carteira de projetos da prefeitura, comportando, na época, 253 projetos das mais diversas áreas - cada área com seus respectivos gerentes de projeto. $\mathrm{O}$ gestor do PMO apontou como principais facilitadores na implantação e realização das funções do escritório de projetos: o alinhamento com a cúpula da organização, as lideranças, o método e o conhecimento técnico utilizado na construção do PMO, oferecido por meio de treinamento realizado tanto para a equipe do PMO como para os gerentes de projetos, além da utilização de ferramentas informatizadas. O que condiz com o pensamento de Maximiano e Anselmo (2006), ao ressaltarem que o apoio da cúpula da organização ao gestor do escritório de projetos é de extrema importância para o desempenho dos projetos organizacionais.

Revista Brasileira de Políticas Públicas e Internacionais, v.4, n.1, julho/2019, pp. 05-28. 
MELO, Antony; DOLCI, Décio Bittencourt; CERQUEIRA, Lucas Santos. Escritórios de Gestão de Projetos no Setor Público à Luz do Paradigma da Nova Administração Pública

Já a cultura do funcionalismo público brasileiro é a principal dificuldade encontrada na implantação do PMO, de acordo com o relato do gestor, corroborando com Teixeira e Salles (2006) que apontam a ausência de uma cultura de gerenciamento de projetos no contexto da administração pública, sendo umas das principais dificuldades encontradas pelos escritórios de projetos.

De acordo com o gestor do PMO, o sucesso dos projetos está intimamente relacionado com os prazos de entrega planejados, em função das ações e metas a serem cumpridas. Por outro lado, o sucesso do PMO é considerado como a institucionalização do mesmo. O reconhecimento, por parte da organização como um todo, do PMO como órgão vital e não apenas como mecanismo de controle, proporcionando, nesse sentido, maior aproximação e integração entre as Secretarias e o Prefeito.

A introdução de um método de planejamento e o desenvolvimento de capacidades de mensuração e controle das ações são percebidos como os principais resultados pelo gestor do escritório de projetos, uma vez que tais características eram ausentes antes da chegada do PMO. O custo proposto pelo investimento em um PMO é encarado como uma necessidade, um investimento muito importante. Apesar de ser considerado caro, devido à necessidade de uma consultoria, a previsão de retorno sobre o investimento é alta, pois, ao longo do tempo, são acumulados resultados importantes em termos financeiros e sociais.

O PMO da Prefeitura de Pelotas gerencia todos os projetos da cidade através de um software, desenvolvido por servidores da própria prefeitura especificamente para as necessidades do escritório. Este programa funciona inteiramente via Internet (full web), ou seja, os gestores e gerentes de projeto podem acessar de qualquer local e a qualquer momento. É por meio dessa ferramenta que são monitorados, de forma centralizada e padronizada, todos os cronogramas e orçamentos dos projetos.

O software ainda permite ao gestor o acompanhamento das responsabilidades em relação aos projetos, facilitando e coordenando o compartilhamento de informações. Outra prática do PMO é a padronização de políticas e procedimentos, permitindo melhor controle e fluxo dos projetos. Nesse sentido, conforme o entrevistado, o PMO lidera a disseminação de

Revista Brasileira de Políticas Públicas e Internacionais, v.4, n.1, julho/2019, pp. 05-28. 
MELO, Antony; DOLCI, Décio Bittencourt; CERQUEIRA, Lucas Santos. Escritórios de Gestão de Projetos no Setor Público à Luz do Paradigma da Nova Administração Pública

melhores práticas de gerenciamento de projetos para toda organização, capaz de mudar a ausência de cultura voltada para resultados.

\subsection{PMO no Governo do Estado do Rio Grande do Sul}

A Unidade de Gestão de Projetos Estruturantes (DEPROJ) atua como um PMO instalado na Secretaria do Planejamento, Mobilidade e Desenvolvimento Regional do Estado do Rio Grande do Sul. Em 2007, o governo do Rio Grande do Sul tomou conhecimento do PMO através do Governo do Estado de Minas Gerais e decidiu implementar as práticas do escritório de projetos no Estado. O motivo foi a necessidade de acompanhar os principais projetos do governo, baseado no modelo utilizado em Minas Gerais, através da introdução de uma metodologia mais organizada em gerenciamento de projetos, o guia PMBOK, para a administração pública.

A principal dificuldade encontrada na implantação desse PMO no governo gaúcho foi, justamente, a cultura organizacional institucionalizada na administração pública, mencionada também no caso anterior. O gestor do PMO enfatizou que a falta de uma cultura voltada para o resultado, acompanhamento e monitoramento efetivo de ações foi a maior barreira a ser superada pela organização. Também ressaltou que tempos modernos anseiam por mudanças propositivas em termos de novas políticas de administração.

Similarmente aos resultados obtidos no caso anterior, o gestor do PMO responsável pelos projetos do Governo do Estado ressaltou o alinhamento com a cúpula da organização como crítico para o sucesso da iniciativa, uma vez que o desempenho do PMO está diretamente relacionado a esse fator. Definindo, assim, essa característica tanto como facilitador das funções do PMO como inibidor, a depender do grau de alinhamento.

Tanto para o projeto quanto para o PMO, o entendimento de sucesso é o atingimento de um alto nível de execução dos projetos, em termos de escopo, tempo e custos. Ou seja, é a sincronia entre o planejamento e a execução de um projeto. Dada essa condição, o gestor reitera que o sucesso vem quando a execução financeira reflete a execução física do projeto.

Outra vez, o presente caso vai ao encontro do que foi denotado no caso anterior, no que se refere à introdução de uma metodologia de planejamento e gestão de projetos no contexto da

Revista Brasileira de Políticas Públicas e Internacionais, v.4, n.1, julho/2019, pp. 05-28. 
MELO, Antony; DOLCI, Décio Bittencourt; CERQUEIRA, Lucas Santos. Escritórios de Gestão de Projetos no Setor Público à Luz do Paradigma da Nova Administração Pública

administração pública produzindo resultados relevantes a partir da implantação do PMO. Isso mostra, novamente, que a cultura organizacional no setor público, frente às mudanças, técnicas e práticas impostas pelo escritório de gerenciamento de projetos, toma um caráter voltado para o resultado, assim como ocorre nas organizações privadas. Percebe-se que a presença do PMO na organização transforma positivamente a cultura organizacional do setor público.

Em 2007, foi realizado o investimento para implantar o PMO na organização. O custo inicial foi principalmente o referente à consultoria recebida. Em um primeiro momento, o retorno desse investimento foi incipiente. Entretanto, ao longo do tempo, observando-se um prazo maior, o ganho, em termos de resultados, foi transformador, pois mudou-se toda uma cultura organizacional a partir desse investimento que, atualmente, não custa nada a mais para o Estado, visto que o escritório é composto por servidores efetivos.

A principal função do PMO é garantir que os projetos mais importantes sejam priorizados em termos de administração. Para isso, foi adquirido um software, desenvolvido pela Fundação Getulio Vargas (FGV), baseado nas necessidades do Governo. É através dele que os principais projetos são monitorados. Além de funcionar como unidade de disseminação de práticas gerenciais, o PMO também presta consultoria em gerenciamento de projetos, para os demais órgãos e departamentos do Estado.

\subsection{Síntese dos Resultados}

Após a análise individual dos casos, apresenta-se uma síntese dos resultados no quadro 2, destacando práticas e funções operacionalizadas, motivos da adoção, facilidades, dificuldades e benefícios percebidos.

Revista Brasileira de Políticas Públicas e Internacionais, v.4, n.1, julho/2019, pp. 05-28. 
MELO, Antony; DOLCI, Décio Bittencourt; CERQUEIRA, Lucas Santos. Escritórios de Gestão de Projetos no Setor Público à Luz do Paradigma da Nova Administração Pública

Quadro 2: Síntese dos resultados

\begin{tabular}{|c|c|}
\hline $\begin{array}{l}\text { Práticas/ } \\
\text { Funções }\end{array}$ & $\begin{array}{l}\text { Disponibilização de recursos compartilhados; Identificação e desenvolvimento de } \\
\text { metodologias; Identificação e desenvolvimento de padrões e melhores práticas; } \\
\text { Padronização de políticas, procedimentos e formulários (templates); } \\
\text { Gerenciamento e repositório centralizado de riscos para todos os projetos; } \\
\text { Escritório central para gerenciamento de ferramentas computacionais; } \\
\text { Coordenação central da comunicação para projetos; Plataforma de mentoria } \\
\text { (aconselhamento e consultoria) para gerentes de projetos; Monitoramento } \\
\text { centralizado de todos os cronogramas e orçamentos dos projetos; Coordenação } \\
\text { geral do gerenciamento da qualidade. }\end{array}$ \\
\hline Motivos & $\begin{array}{l}\text { Necessidade de acompanhar e monitorar todos os projetos de forma organizada e } \\
\text { padronizada; Necessidade de acompanhar as responsabilidades em relação aos } \\
\text { projetos. }\end{array}$ \\
\hline Facilidades & $\begin{array}{l}\text { Alinhamento com a alta administração; as lideranças presentes na gestão da } \\
\text { implantação; Método e conhecimento técnico da Consultoria. }\end{array}$ \\
\hline Dificuldades & Ausência de cultura de gerenciamento de projetos; Ingerência política. \\
\hline Benefícios & $\begin{array}{l}\text { Introdução de um método de planejamento de gestão de projetos; Capacidade de } \\
\text { mensuração de projetos e controle das ações. }\end{array}$ \\
\hline
\end{tabular}

Fonte: Elaboração Própria (2017).

Os resultados indicam que as principais funções do PMO, no contexto da administração pública, são o monitoramento centralizado e padronizado de projetos e a prestação de consultoria de gerenciamento de projetos no âmbito da organização. Por outro lado, verificouse que a principal dificuldade encontrada pelo PMO no setor público é a cultura do funcionalismo público do Brasil.

Verificando as características do PMO na prática e comparando com os princípios da administração pública gerencial (Bresser-Pereira, 1998), percebeu-se a convergência dos seguintes pressupostos, conforme o quadro 3: (a) utilização de métodos e técnicas do setor privado no setor público; (b) gerenciamento da qualidade; (c) cultura organizacional voltada para a eficiência; (d) planejamento e definição clara de objetivos; e (e) foco no cidadão, ainda que se perceba apenas poucas falas diretamente direcionadas a essa última questão nas entrevistas.

Revista Brasileira de Políticas Públicas e Internacionais, v.4, n.1, julho/2019, pp. 05-28. 
MELO, Antony; DOLCI, Décio Bittencourt; CERQUEIRA, Lucas Santos. Escritórios de Gestão de Projetos no Setor Público à Luz do Paradigma da Nova Administração Pública

Quadro 3: Pressupostos convergentes

\begin{tabular}{|c|c|}
\hline $\begin{array}{l}\text { Pressupostos } \\
\text { convergentes }\end{array}$ & Alguns trechos das entrevistas \\
\hline $\begin{array}{l}\text { (a) Utilização de } \\
\text { métodos e técnicas do } \\
\text { setor privado no setor } \\
\text { público }\end{array}$ & $\begin{array}{l}\text { Gestor 1: "Nossa plataforma implementada, então, considerou[...] Para uma } \\
\text { plataforma de gerenciamento de projetos as seguintes dimensões: alinhamento } \\
\text { estratégico, metodologia, informatização, estrutura organizacional e competências." } \\
\text { Gestor 2: "E com toda metodologia do PMBOK, do PMO, o que competia as } \\
\text { partes. Fizemos um elenco da carteira de projetos e ali começou a nossa sistemática } \\
\text { que foi, ao longo do tempo de } 2007 \text { até agora, só foi evoluindo tanto em termos de } \\
\text { ferramenta quanto de aperfeiçoamento do método de disseminação dessa cultura." }\end{array}$ \\
\hline $\begin{array}{l}\text { (b) Gerenciamento da } \\
\text { qualidade }\end{array}$ & $\begin{array}{l}\text { Gestor 1: "Padrões e melhorias de práticas fazem parte. É justamente, praticamente } \\
\text { o dia a dia de um escritório. Ou seja, esses padrões que nós estabelecemos como } \\
\text { ferramenta informatizada, como método PDCA, como conceitos pra gestão e } \\
\text { monitoramento, precisam ser implementados." } \\
\text { Gestor: 2: "Identificação e desenvolvimento de metodologia sim, nós fazemos isso. } \\
\text { Padrões e melhores práticas também, isso aí a gente foi acumulando a gente já em } \\
\text { até um material produzido. Normalmente a cada final de governo a gente faz um } \\
\text { resumo." }\end{array}$ \\
\hline $\begin{array}{l}\text { (c) Cultura } \\
\text { organizacional voltada } \\
\text { para a eficiência }\end{array}$ & $\begin{array}{l}\text { Gestor 1: "A abordagem (do PMO), então, considera planejamento estratégico, } \\
\text { processos rotineiros - com garantia de qualidade e eficiência -, melhoria nesses } \\
\text { próprios processos de monitoramento e planejamento, e a expansão, } \\
\text { consequentemente, de melhores serviços" } \\
\text { Gestor 2: "Enfim, o principal para que nós tenhamos, daqui mais um tempo, } \\
\text { resultados práticos daquilo que foi proposto é através desta mudança de cultura que } \\
\text { o escritório está promovendo no âmbito do governo como um todo." }\end{array}$ \\
\hline $\begin{array}{l}\text { (d) Planejamento e } \\
\text { definição clara de } \\
\text { objetivos }\end{array}$ & $\begin{array}{l}\text { Gestor 1: "Focando, via controle, todas essas características. Ou seja, não existe } \\
\text { controle, tu passa a ter um certo controle, não existe identificação bem clara de } \\
\text { quem faz o que e quando, tu passa a teres isso contigo." } \\
\text { Gestor 2: "Nós, de uma maneira assim bastante pragmática, os resultados reais se } \\
\text { deram num nível mais de cultura de planejamento e de metodologia de } \\
\text { acompanhamento de projetos." }\end{array}$ \\
\hline (e) Foco no cidadão & $\begin{array}{l}\text { Gestor 1: "Como algo de fato, que lá um decreto criou, alguém implementou, } \\
\text { gerou resultados, e que deve e precisa ser proposto pra um melhor serviço público e } \\
\text { acompanhamento de entregas na verdade. É o que todo mundo busca e corre atrás } \\
\text { pra que se execute e, consequentemente, o serviço lá pro cidadão chegue muito } \\
\text { melhor." } \\
\text { Gestor 2: "Então este foi o motivo principal (adoção do PMO). Organizar para } \\
\text { termos condições de não somente o governo ficar na intenção através de seu plano } \\
\text { de governo, mas também conseguir resultados dentro daquilo a que se propunha. } \\
\text { Este foi o motivo pelo que se começou a tomar uma forma mais organizada, } \\
\text { profissionalizada com metodologia." }\end{array}$ \\
\hline
\end{tabular}

Fonte: Elaboração própria (2017).

Revista Brasileira de Políticas Públicas e Internacionais, v.4, n.1, julho/2019, pp. 05-28. 
MELO, Antony; DOLCI, Décio Bittencourt; CERQUEIRA, Lucas Santos. Escritórios de Gestão de Projetos no Setor Público à Luz do Paradigma da Nova Administração Pública

\subsection{Discussão dos Resultados à Luz da NPM}

Primeiramente, ao analisar a implantação do PMO em organizações públicas, verificouse a necessidade de aplicação de métodos e procedimentos utilizados pelas organizações privadas para melhor aproveitamento do escritório, no que tange ao seu caráter gerencial. As organizações utilizaram o bechmark e contrataram empresas de consultoria especializadas. Tal característica é evidenciada a partir da relação entre a reforma administrativa do Estado, que resultou na administração pública gerencial, e seus pressupostos. Visto que a administração pública gerencial traz a adoção de métodos e técnicas utilizados nas organizações privadas para o setor público (Abrúcio, 1997; Bresser-Pereira, 1998; Sechhi, 2009). Também se notou a importância do PMO no que diz respeito à execução de funções essenciais e prestação de consultoria para os demais departamentos da organização.

Nos dois casos estudados, constatou-se que o PMO gerencia todos ou, pelo menos, os principais projetos da organização, ressaltando sua importância como organismo vital. Ambos os casos da administração pública direta apresentaram como maior dificuldade enfrentada pelo escritório de projetos a cultura do funcionalismo público, que se apresenta como falta de atributos de empreendedorismo, capacidade de inovação, ousadia e competência técnica (Carbone, 2000). Esta dificuldade também foi evidenciada nos estudos de Teixeira e Salles (2006) e Furtado, Fortunato e Teixeira (2011), corroborando com os dados obtidos no atual estudo. Também ficou claro que, a partir das respostas dos Gestores, o PMO atua como unidade de disseminação de uma cultura voltada para resultados, diferentemente da anterior. A descentralização voltada para o foco nos resultados, e não no controle, obtida a partir da Nova Administração Pública, influenciou essa mudança de cultura e convergiu para os interesses do PMO.

Outro ponto de destaque é que, em ambos os casos do Poder Executivo, o alinhamento com a alta administração é o principal facilitador tanto no desempenho das funções do PMO quanto na sua implantação. Estudos de Carvalho e Piscopo (2014) corroboram com essa análise, pois apontam que a confiança da alta gestão e o alinhamento estratégico do PMO com os objetivos organizacionais, além de facilitadores, também são viabilizadores da implantação. Novamente, nota-se a influência da administração pública gerencial na relação das funções do

Revista Brasileira de Políticas Públicas e Internacionais, v.4, n.1, julho/2019, pp. 05-28. 
MELO, Antony; DOLCI, Décio Bittencourt; CERQUEIRA, Lucas Santos. Escritórios de Gestão de Projetos no Setor Público à Luz do Paradigma da Nova Administração Pública

PMO com o desempenho organizacional, pois a descentralização administrativa, através da delegação de autoridade para os administradores públicos transforma gerentes crescentemente autônomos, focados no resultado.

Em todos os casos estudados, o resultado mais explícito foi a introdução de um método de planejamento de gestão de projetos, visto que anteriormente não havia um caráter voltado objetivamente para padrões e técnicas de gestão de projetos. O PMO atua como responsável pela disseminação da metodologia de gestão de projetos nas organizações públicas, treinando os profissionais envolvidos e ratificando a importância desse para os demais (Carvalho \& Piscopo, 2014). Apesar de o PMO e a Nova Administração Pública apontarem para práticas de gestão mais eficientes, Peci, Pierante e Rodrigues (2008), ao analisar a dicotomia eficiência e transparência, afirmam que a reforma administrativa do Estado de 1995 não levou em consideração as realidades díspares do país, ou seja, não se considerou as complexidades regionais, faltando flexibilidade na implementação dos princípios da Administração Pública Gerencial. Além disso, segundo Rezende (2004), a cultura burocrática aparece como um sério impedimento para mudanças institucionais, pois quando a reforma aponta para a necessidade de mudança, através de princípios como flexibilidade e autonomia, a cultura burocrática reage.

\section{Considerações Finais}

Este artigo utilizou-se de dois estudos de caso, um na esféra municipal outro na estadual, a fim de compreender a adoção dos Escritórios de Gestão de Projetos (PMOs) no setor público a partir da identificação dos diferentes facilitadores e inibidores, tanto na implantação como na realização das funções do PMO, associando tanto os motivos das iniciativas como as funções executadas aos benefícios no desempenho organizacional sob a perspectiva do paradigma da Nova Administração Pública.

A partir dos resultados analisados, e da relação entre o paradigma da Nova Administração Pública e o gerenciamento de projetos, foi possível entender melhor a influência da administração pública gerencial na adoção de Escritórios de Gestão de Projetos nas organizações públicas, uma vez que a reforma administrativa do Estado trouxe pressupostos que vão em direção às técnicas e métodos aplicados no setor privado e também no PMO.

Revista Brasileira de Políticas Públicas e Internacionais, v.4, n.1, julho/2019, pp. 05-28. 
MELO, Antony; DOLCI, Décio Bittencourt; CERQUEIRA, Lucas Santos. Escritórios de Gestão de Projetos no Setor Público à Luz do Paradigma da Nova Administração Pública

Considera-se que os objetivos foram, então, alcançados. A identificação dos diferentes facilitadores e inibidores relacionados a implatação e funções dos PMOs possibilitou um melhor entendimendo sobre a contextualização do paradigma da Nova Administração Pública e o gerenciamento de projetos, em termos de construção histórica dos pressupostos comuns ao PMO de setores públicos e a NPM.

Os Escritórios de Gestão de Projetos apresentam-se como uma alternativa para prover métodos e práticas de gestão de projetos capazes de melhorar o desempenho das organizações públicas. Além disso, orienta a organização para resultados objetivos e mensuráveis, introduzindo na sua rotina metodologias e práticas gerenciais, possibilitando, assim, melhores e maiores benefícios para a sociedade.

Como principal limitação deste estudo, aponta-se o pequeno número de organizações investigadas, a seleção dos casos por conveniência e a impossibilidade de generalização dos achados, em virtude do caráter exploratório dos estudos de caso realizados. Apesar de haver poucas organizações públicas do Poder Executivo com PMOs em suas estruturas, podem existir outras práticas não exploradas, influenciadas pelas especificidades de cada região e ideologias políticas diversas. Assim, sugere-se examinar estudos correlatos e realizar novas pesquisas abrangendo outras organizações de localidades diferentes das apresentadas neste artigo.

\section{Referências}

Abrúcio, F. L. (1997). O impacto do modelo gerencial na administração pública: um breve estudo sobre a experiência internacional recente. Cadernos ENAP, Brasília, 10.

Anderson, P. (1995). Balanço do neoliberalismo. In: Sader, E. (Org.). Pós- neoliberalismo - As políticas sociais e o Estado democrático. Rio de Janeiro: Paz \& Terra.

Aubry, M., \& Hobbs, B. (2011). A fresh look at the contribution of project management to organizational performance. Project Management Journal, 42, 3-16.

Bourne, M., Mills, J., Wilcox, M., Neely, A., \& Platts, K. (2000). Designing, implementing and updating performance measurement systems. International Journal of Operations \& Production Management, 20 (7), 754-771.

Bresser-Pereira, L. C. (1998). Uma reforma gerencial da Administração Pública no Brasil.

Revista Brasileira de Políticas Públicas e Internacionais, v.4, n.1, julho/2019, pp. 05-28. 
MELO, Antony; DOLCI, Décio Bittencourt; CERQUEIRA, Lucas Santos. Escritórios de Gestão de Projetos no Setor Público à Luz do Paradigma da Nova Administração Pública

Revista do Serviço Público, 49, 5-42.

Bryde, D. J. (2003). Modelling Project Management Performance. International Journal of Quality \& Reliability Management, 20 (2), 229-254.

Burrel, G.; \& Morgan, G. (1979). Sociological Paradigms and Organizational Analysis. London: Heinemann.

Carbone, P. P. (2000). Cultura organizacional do setor público brasileiro: desenvolvendo uma metodologia de gerenciamento da cultura. Revista de Administração Pública, 34, 1-5.

Carneiro, M. PMO no setor público. (2012). In: BARCAUI, A. PMO: Escritórios de Projetos, Programas e Portfólio na prática (pp. 104-134). Rio de Janeiro: Brasport.

Carvalho, K. E. M.; Piscopo, M. R. (2014). Fatores de Sucesso da Implantaçao de um PMO: um caso na Administraçao Pública. Revista Gestão \& Tecnologia, 14, 56-78.

Cezar, L.C.; Behr, R. R.; Reis, M. C. T.; Santos, S. N.; \& Barbosa, T. R. C. G. (2015, setembro) A Comunicação Governamental em Tempos da New Public Management: Proposta de um Modelo de Análise da Comunicação em Políticas Públicas. Anais do Encontro Nacional da Associação Nacional de Pós-Graduação e Pesquisa em Administração, Belo Horizonte, MG, Brasil.

Cintra, R. F., \& Vieira S. F. A. (2007, setembro). O Processo de Implantação da Gestão de Projetos em Órgãos Públicos: um Estudo de Caso na Prefeitura Municipal de Dourados/MS. Anais do Encontro Nacional da Associação Nacional de Pós-Graduação e Pesquisa em Administração, Rio de Janeiro, RJ, Brasil.

Cleland, D. I., \& Ireland, L. R. (2002). Gerência de projetos. Rio de Janeiro: Reichmann \& Affonso.

Creswell, J. W. (2007). Projeto de Pesquisa: métodos qualitativo, quantitativo e misto. $2{ }^{a}$ Ed., São Paulo: Artmed.

Costa, A. M., Lima, D. M. C., Barros, D. F., \& Martins, P. E. M. (2010, novembro). Alinhando Discursos: As Práticas Empreendedoras das Empresas Juniores à Luz da New Public Management. Anais do Encontro de Administração Pública da Associação Nacional de PósGraduação e Pesquisa em Administração, Vitória, ES, Brasil.

Costa, F. L., \& Costa, E. M. L. (2016). Nova história da administração pública brasileira: pressupostos teóricos e fontes alternativas. Revista de Administração Pública, 50, 215-236.

Englund, R. L., Graham, R. J., \& Dinsmore, P. C. (2003). Creating the project office. San

Revista Brasileira de Políticas Públicas e Internacionais, v.4, n.1, julho/2019, pp. 05-28. 
MELO, Antony; DOLCI, Décio Bittencourt; CERQUEIRA, Lucas Santos. Escritórios de Gestão de Projetos no Setor Público à Luz do Paradigma da Nova Administração Pública

Francisco: Jossey-Bass.

Furtado, M., Fortunato, G., \& Teixeira, A. (2011). A percepção dos gestores da área pública sob a política de gerenciamento de projetos. Revista Eletrônica Sistemas \& Gestão, 6, 167-183.

Guimarães, T. A. (2000). A nova administração pública e a abordagem da competência. Revista de Administração Pública, 34, 125-140.

Kerzner, H. (2009). Project management: a systems approach to planning, scheduling, and controlling. 10th ed. New Jersey: John Wiley \& Sons, Inc., 1122 p.

Maximiano, A. C. A., \& Anselmo, J. L. (2006). Escritório de gerenciamento de projetos: um estudo de caso. Revista de Administração da Universidade de São Paulo, 41, 394-403.

Meredith, J. R., \& Mantel Jr., S. J. (2003). Administração de projetos: uma abordagem gerencial. Rio de Janeiro: LTC, 425p.

Müller, R., \& Turner, R. (2007). The influence of project managers on project success criteria and project success by type of project. European Management Journal, 25 (4), 298-309.

Olateju, O. I., Abdul-azeez, I. A., \& Alamutu, S. A. (2011). Project management practice in Nigerian public sector - an empirical study. Australian Journal of Business and Management Research, 1(8), 1-8.

Parchami Jalal, M., \& Matin Koosha, S. (2014). Identifying organizational variables affecting project management office characteristics and analyzing their correlations in the Iranian project-oriented organizations of the construction industry. International Journal of Project Management.

Peci A., Pieranti O. P., \& Rodrigues S. (2008). Governança e New Public Management: convergências e contradições no contexto brasileiro. Revista Organizações \& Sociedade $(O \& S), 15(46)$.

Pestana, C. V. S., \& Valente, G. V. P. (2010). Gerenciamento de Projetos na Administraçao Pública: Da Implantaçao do Escritório de Projetos à Gestão de Portfólio na Secretaria de Estado de Gestão e Recursos Humanos do Espírito Santo. Congresso de Gestão Pública (CONSAD), Brasília, Brasil, 3.

Peters, G. B. (2008). Os dois futuros do ato de governar: processos de descentralização e recentralização no ato de governar. Revista do Serviço Público, 59(3), 289-307.

Pieranti, O. P., Rodrigues, S., \& Peci, A. (2007, setembro). Governança e New Public Management: Convergências e Contradições no Contexto Brasileiro. Anais do Encontro

Revista Brasileira de Políticas Públicas e Internacionais, v.4, n.1, julho/2019, pp. 05-28. 
MELO, Antony; DOLCI, Décio Bittencourt; CERQUEIRA, Lucas Santos. Escritórios de Gestão de Projetos no Setor Público à Luz do Paradigma da Nova Administração Pública

Nacional da Associação Nacional de Pós-Graduação e Pesquisa em Administração, Rio de Janeiro, RJ, Brasil.

PM SOLUTIONS. (2014). The State of the Project Management Office (PMO). Recuperado em 20/11/2015, de http://www.pmsolutions.com/.

Project Management Institute. (2014). PMBOK: Um Guia do Conhecimento em Gerenciamento de Projetos (Guia PMBOK). Quinta Edição. Pennsylvania : PMI Publications, 567 p.

Project Management Institute. (2006). Government Extension to the PMBOK® guide. 3 ed. Four Campus Boulevard, Newtown Square, PA.

Rezende, D. A. (2004, novembro). Planejamento estratégico municipal e suas relações com as políticas de gestão de cidades e com a teoria New Public Management. Anais do Encontro de Administração Pública da Associação Nacional de Pós-Graduação e Pesquisa em Administração, Rio de Janeiro, RJ, Brasil.

Rua, M. G. (1997). Desafios da administração pública brasileira: governança, autonomia, neutralidade. Revista do Serviço Público, 48 (3).

Secchi, L. (2009). Modelos organizacionais e reformas da Administração pública. Revista de Administração Pública, 43 (2), 347-369.

Shenhar, A. J., Levy, O., \& Dvir, D. (1997). Mapping the dimensions of project success. The Professional Journal of the Project Management Institute, 28 (2), 5-13.

Teixeira, R. M.; Salles, F. C. (2006). Gestão de Portfólio: A atuação da SEGEP. Recuperado em 13/07/2015, de http://www.pmiba.org.br/uploads/tinymce/files/portf_lio_segep.pdf.

Valle, A. B., Soares, C. A. P., Finocchio Jr., J., \& Silva, L. S. F. (2010). Fundamentos de Gerenciamento de Projetos. $2^{\mathrm{a}}$ ed. Rio de Janeiro: Editora FGV, 237 p.

Walton, E. J., \& Dawson, S. (2001). Managers' perceptions of criteria of organizational effectiveness. Journal of Management Studies, 38 (2), 173-199.

Westerveld, E. (2003). The Project Excellence Model®: linking success criteria and critical success factors. International Journal of Project Management, 21, 411-418.

Yin, R. K. (2001). Estudo de caso: planejamento e métodos. Segunda Edição. Porto Alegre: Bookman, $200 \mathrm{p}$.

Revista Brasileira de Políticas Públicas e Internacionais, v.4, n.1, julho/2019, pp. 05-28. 